\title{
XXXII. On the recalculation of certain specific heats at high temperatures, and the specific heat of water
}

\section{William Sutherland M.A. B.Sc.}

To cite this article: William Sutherland M.A. B.Sc. (1888) XXXII. On the recalculation of certain specific heats at high temperatures, and the specific heat of water, Philosophical Magazine Series 5, 26:160, 298-305, DOI: 10.1080/14786448808628265

To link to this article: http://dx.doi.org/10.1080/14786448808628265

冓 Published online: 29 Apr 2009.

Submit your article to this journal $₫$

Џll Article views: 7

Q View related articles $\sqsubset$ 
measurements as a whole. For although it is likely that errors may occur in some of the individual members, it is hardly possible that the whole are erroneous. It will therefore follow that undulations of a length of about one sixty-fourth of an inch (taking the mean measurement) accompany the disruptive discharge.

The photographs from which the figures in the Plate are copied were taken for me by Mr. Dunscombe, of Bristol, and were printed from the negatives without the latter being touched in any way.

Note, June 9, 1888.-Since the above was written, I have been informed by Prof. Rücker that he has an apparatus in his possession, made by the late Dr. Guthrie, which gives somewhat similar results. This was copied from one exhibited at the Loan Exhibition of Scientific Apparatus in 1879. It consists of an elliptical dish with vertical walls. Sand is scattered over the bottom, a glass plate placed over the top, and a series of electric sparks produced at one focus of the ellipse. The sand will then be found to arrange itself in a series of circular curves around the other focus. The curves thus produced bear a striking resemblance to those exhibited in the Plate accompanying this paper, and are of course due to the same cause.

XXXII. On the Recalculation of certain Specific Heats at High Temperatures, and the Specific Heat of Water. By William Sutherland, M.A., B.Sc.*

I $N$ the course of some work on molecular physics I was led 1 to search for some accurate measurements of the specific heats of liquids at high temperatures, and found that, although Hirn had conducted some good experiments, his results had not been accepted on account of their disagreement with those of Regnault. Thus, while for the heat necessary to raise ether from $0^{\circ}$ to $t$ Hirn gives the formula

Regnault gives

$$
q=\cdot 564 t+\cdot 000799 t^{2}-\cdot 0_{5} 268 t^{3}+\cdot 0_{7} 181 t^{4}
$$

For alcohol Hirn gives

$$
q=\cdot 529 t+\cdot 000296 t^{2}
$$

$$
q=\cdot 4229 t+\cdot 00274 t^{2}-\cdot 0_{4} 132 t^{3}+\cdot 0_{7} 506 t^{4},
$$

while Regnault's formula is

$$
q=\cdot 5475 t+\cdot 00112 t^{2}+\cdot 0_{5} 221 t^{3}
$$

The great differences between the values for the specific heats

$$
\text { * Communicated by the Author. }
$$


at $0^{\circ}$ given by these formulæ have naturally discredited Hirn's results, seeing that Regnault's values at $0^{\circ}$ are certainly nearly correct. In the case of $\mathrm{CS}_{2}$ and $\mathrm{CCl}_{4}$ Hirn's results are in much better agreement with Regnault's ; but the above discrepancies, as they condemned Hirn's method, condemned therefore the whole of his results.

But by recalculating the specific heats from Hirn's experimental data $I$ have been able to bring his results at high temperatures into good agreement with Regnault's at low, and so to obtain expressions for the specific heats of ether, alcohol, $\mathrm{CS}_{2}$, and $\mathrm{CCl}_{4}$ from $0^{\circ}$ up to $140^{\circ}$.

Hirn (Ann. de Chim. et de Phys. sér. 4, x.) adopted the method of cooling, but on so large a scale that he was able to avoid the difficulties usually inherent in that method. The vessel in which the liquids were heated was of about 8 litres capacity, and might be regarded as the bulb of a huge thermometer, the stem of which was 11 metres long and was filled with mercury; the pressure of the mercury-column permitted the temperature of the volatile liquids to be raised to $160^{\circ}$. The size of this apparatus allowed of the introduction of an efficient stirring mechanism to keep the whole mass of liquid uniform in temperature; thus the radical difficulty of the method of cooling when used on a small scale was avoided.

When the liquid in the bulb was heated, the overflow of mercury at the top of the stem enabled Hirn to measure very accurately the expansion of the liquid up to high temperatures, and gave him a connexion between the volume and temperature of the liquid at any moment in the process of cooling. In this way he succeeded in measuring the rate of cooling at temperatures ranging from $160^{\circ}$ to $40^{\circ}$.

Unfortunately he adopted a cumbersome and inaccurate method of treating his experimental numbers in order to obtain from them the specific heats. Instead of estimating the rate of cooling direct from the experimental numbers, he found an empirical formula connecting the observed times and temperatures, and then from this, by differentiation, got the rate of change of temperature. But it is obvious that this method becomes dangerous at low temperatures ; for then the rate of change becomes slow, and inaccuracy in the formula which may not appear of appreciable importance in affecting the absolute value of the temperature at a given time, may seriously affect the value of the rate of change. In other words, if the ordinate of a curve is approaching a stationary value, a formula may represent the absolute values of the ordinates fairly well and yet give large errors in the values of the small slope of the tangent. 
Although Hirn's formulæ represent his experiments excellently, yet they introduce in this manner a certain amount of inaccuracy into his final determinations of the specific heats. However, it is easy to calculate from his full published data the correct values.

The cooling of the large bulb is due to two causes-(1) radiation, and (2) introduction of cool liquid from the stem. As it is the rate of cooling due to radiation only that is required in the method of cooling, we must calculate this from the actual rate of cooling.

If, in time $d t$, a mass $d p$ passes from the stem where its temperature is $i$ to the bulb where it is $\theta$, then if $k$ is the specific heat at $\theta$, and $k^{\prime}$ is the mean specific heat between $i$ and $\theta$, the cooling effect produced by $d p$ on the mass $p$ in the bulb is

$$
d p k^{\prime}(\theta-i) / k p \text {. }
$$

If, then, $d \theta$ is the actual amount of cooling, and $d r$ the amount due to radiation in time $d t$, we have

$$
\frac{d \theta}{d t}=\frac{d r}{d t}+\frac{d p}{d t} \frac{k^{\prime}(\theta-i)}{k p} \text {. }
$$

Now $d p / d t$ is given by Hirn in his experiments on the rate of expansion, so also is $p ; k^{\prime} / k$ can be estimated with sufficient accuracy from Regnault's formula for lower temperatures ; $i$ can be taken as the temperature of the surrounding air, though that is too low; but the whole of the last term is small compared to the others, so that roughness in its estimation does not produce much effect in the first calculation of specific heats.

From the above equation, then, we get the required rate of cooling due to radiation only.

Let $\mathrm{P}$ be the water-equivalent of the bulb and stirrer ; then if the rate of cooling of water at temperature $\theta$, of specific heat $k_{1}$, is $v_{1}$, while $p_{1}$ is the mass of water in the bulb, then, by the usual equation for the method of cooling, we have

$$
(p k+\mathrm{P}) v=\left(p_{1} k_{1}+\mathrm{P}\right) v_{1},
$$

where $v$ stands for $d r / d t ; v$ and $v_{1}$ are calculated from Hirn's data, as explained above; $p, p_{1}$, and $\mathrm{P}$ are given by Hirn; whence we can calculate $k$ if we take the values of $k^{\prime}$ from Regnault's determinations. A communication by Velten (Wied. Ann. xxi. 1884) would seem to show that Regnault's values for the specific heat of water at high temperatures are altogether worthless; but I shall show, in an addendum to this paper, that the apparent discrepancies in Regnault's 
published numbers can be clearly traced to an error of copying, which, however, has had no effect on the original calculations, so that the values of the specific heat at different temperatures have been found correctly.

The actual rates of cooling at different temperatures were obtained from Hirn's data by dividing change of temperature by time elapsed during change and taking this as the rate of cooling at the mean of the extreme temperatures. The actual rates thus found were plotted and a curve drawn amongst the points. From the curve were then taken for use in the formula the values of $v$ for $140^{\circ}, 120^{\circ}, 100^{\circ}$, and $80^{\circ}$. As the curves lay very steadily amongst the points down to $80^{\circ}$ and not so well below that, it seemed advisable not to use Hirn's results below that temperature, but to adopt Regnault's data at lower temperatures.

The following table contains in the first row for each substance the actual rates of cooling; in the second the rates due to radiation only in degrees per minute; and in the third the specific heats.

\begin{tabular}{|c|c|c|c|c|}
\hline Substance. & $140^{\circ}$. & $120^{\circ}$. & $100^{\circ}$. & $80^{\circ}$. \\
\hline Water ...... & $\begin{array}{r}.775 \\
.703 \\
1.023\end{array}$ & $\begin{array}{r}575 \\
555 \\
1.018\end{array}$ & $\begin{array}{r}410 \\
391 \\
1.013\end{array}$ & $\begin{array}{r}270 \\
-264 \\
1 \cdot 009\end{array}$ \\
\hline Ether & $\begin{array}{l}\ldots \ldots . \\
\cdots \ldots . . \\
\ldots \ldots .\end{array}$ & $\begin{array}{r}1.275 \\
1.008 \\
.803\end{array}$ & $\begin{array}{l}.892 \\
.765 \\
\cdot 736\end{array}$ & $\begin{array}{r}.580 \\
.528 \\
.690\end{array}$ \\
\hline Alcohol & $\begin{array}{c}1 \cdot 22 \\
\cdot 959 \\
.987\end{array}$ & $\begin{array}{l}.92 \\
.781 \\
.909\end{array}$ & $\begin{array}{l}.70 \\
.626 \\
.797\end{array}$ & $\begin{array}{l}\cdot 495 \\
\cdot 459 \\
\cdot 712\end{array}$ \\
\hline $\mathrm{CS}_{2} \ldots \ldots$ & $\begin{array}{c}2 \cdot 225 \\
1 \cdot 86 \\
\cdot 284\end{array}$ & $\begin{array}{r}1 \cdot 625 \\
1 \cdot 424 \\
\cdot 276\end{array}$ & $\begin{array}{c}1 \cdot 15 \\
1 \cdot 05 \\
\cdot 268\end{array}$ & $\begin{array}{l}761 \\
\cdot 715 \\
\cdot 260\end{array}$ \\
\hline $\mathrm{CCl}_{4} \ldots$ & $\begin{array}{l}2 \cdot 12 \\
1 \cdot 756 \\
\cdot 243\end{array}$ & $\begin{array}{r}1 \cdot 57 \\
1.361 \\
\cdot 233\end{array}$ & $\begin{array}{c}1 \cdot 11 \\
.998 \\
.228\end{array}$ & $\begin{array}{l}\cdot 74 \\
.685 \\
.219\end{array}$ \\
\hline
\end{tabular}

To obtain the most accurate values of the specific heats of these liquids at $0^{\circ}$, I applied the method of least squares to Regnault's experiments by the ordinary calorimeter method, and combined the results with the above to obtain the following values of the constants in the formula $d q / d \theta=a+b \theta+c \theta^{2}$, where $\theta$ represents temperature $\mathrm{C}$. 


\begin{tabular}{|r|c|c|c|}
\hline & $a$. & $b$. & $c$. \\
\hline Ether $\ldots \ldots$. & .5195 & $0_{3} 887$ & $0_{4} 123$ \\
$\mathrm{CS}_{2} \ldots \ldots \ldots$ & .229 & $0_{3} 391$ & \\
$\mathrm{CCl}_{4} \ldots \ldots$. & $\cdot 198$ & $0_{3} 136$ & $0_{5} 133$ \\
\hline
\end{tabular}

The numbers calculated for alcohol do not join on in $a$ continuous manner with those obtained from Regnault's experiments, so that a single formula of the above type is not competent to represent both series.

Regnault's formula has been given at the beginning of this paper, and may be considered to hold from $-10^{\circ}$ to $50^{\circ}$; the numbers tabulated above give for the specific heat of alcohol from $80^{\circ}$ to $140^{\circ}$ the formula

$$
d q / d \theta=\cdot 445+\cdot 0026 \theta+\cdot 0_{5} 92 \theta^{2} .
$$

If the two series of values given by these formulx are to join on to one another in a continuous manner, there must be a point of inflexion between $50^{\circ}$ and $80^{\circ}$ in the curve which represents the relation of specific heat to temperature.

Now it is a noteworthy fact that Regnault, in his experiments on the total beats of different liquids (that is, the amounts of heat necessary to raise unit mass from $0^{\circ}$ to $t$ and evaporate it at $t$ ) found that alcohol was the only exceptional liquid giving a point of inflexion between $70^{\circ}$ and $80^{\circ}$ in the curve representing the relation of total heat to temperature. The agreement between the position of this point and of that on the specific-heat curve is suggestive of some interesting points in the molecular structure of ethylic alcohol. It would be worth while for some experimenter to determine by actual experiment how the specific heat of alcohol does vary between $50^{\circ}$ and $80^{\circ}$.

\section{Addendum.-On Regnault's Determinations of the Specipic Heat of Water at temperatures above $100^{\circ}$.}

It is a rather remarkable fact in the history of Physics that such complete uncertainty should reign to-day as to the specific heat of water, the standard substance in calorimetry, and a fundamental quantity in the science of energy. Observer 
after observer has devoted himself to the question with every appearance of the most thorough provision for refined accuracy; but seems only to have made " confusion worse confounded." The latest research of any elaborateness is that of Velten previously mentioned. He draws attention to apparently great errors in Regnault's calculations of the specific heat of water from his data, giving a table in which are compared the values given by Regnault and those calculated correctly by himself from Regnault's data. In twenty-seven of the experiments the two sets of values agree well enough; but in the remaining thirteen, while Regnault's results are all greater than unity, those of Velten are all less than unity, the difference between the corresponding values in the two series amounting in one case to nearly four per cent. As the errors could not be ascribed to misprints, Prof. Wiillner wrote to the Paris Academy of Sciences to ask if any explanation could be given for them; but that body appeared to be able to furnish none.

Yet the explanation is simple enough. Regnault, in preparing his table (Mém.del'Acad.xxi.), has, in the thirteen cases, merely copied a wrong series of numbers into the column headed "weight of hot water." I shall be able to show this quite clearly, and to prove that in his calculations he must have used the correct series of numbers. Velten, using Regnault's erroneously tabulated series, necessarily obtains erroneous results in the thirteen cases.

Regnault employed a large calorimeter with a narrow graduated neck. Its capacity, when filled to the zero-mark on the neck, was carefully determined and, with the waterequivalent of the calorimeter, was tabulated for temperatures between $10^{\circ}$ and $30^{\circ}$. The neck was also calibrated, so that the water-equivalent of the calorimeter, when filled to any mark on the neck, could be determined with great accuracy. Let $\mathrm{P}_{0}$ be the water-equivalent of the calorimeter and the water at $t_{0}$ which fills it to the graduation $n_{0}$ on the neck. A weight, $p$, was then withdrawn and determined by weighing. The bot water at $T$ was then introduced, so that the calorimeter was filled to the graduation $n$; the water-equivalent at the resulting temperature $t$ of the calorimeter and its contents was then obtainable from the table; let it be $P$, then the weight of hot water introduced was $\mathrm{P}-\left(\mathrm{P}_{0}-p\right)$. Let $x$ be the mean specific heat between $\mathrm{T}$ and $t$, supposing that between $t$ and $t_{0}$ to be unity, then

$$
x\left(\mathrm{P}-\mathrm{P}_{0}+p\right)(\mathrm{T}-t)=\left(\mathrm{P}_{0}-p\right)\left(t-t_{0}\right) .
$$


But at high temperatures the high-pressure steam projected the hot water with such violence into the calorimeter that it was difficult to regulate the amount of hot water so that the free surface of the water in the calorimeter should be within the graduated neck; Regnault, therefore, had to modify his method slightly. He admitted enough hot water not to raise the surface into the graduated part of the neck; but then added enough of the cold water which he had withdrawn to bring the level of the water amongst the graduations. This small weight of water never exceeded 100 grammes; let it be denoted by $\pi$, then the equation becomes

$$
x\left(\mathrm{P}-\mathrm{P}_{0}+p-\pi\right)(\mathrm{T}-t)=\left(\mathrm{P}_{0}-p+\pi\right)\left(t-t_{0}\right) .
$$

Thus Regnault conducted two series of experiments by slightly different methods ; but he includes all his results in a single table without giving any information as to which belongs to which series. It is easy to see, however, that the second method was used in precisely the thirteen experiments in which the differences occur, namely, those numbered $3,11,12,13,27$, 29,34 to 40 , the last seven corresponding to the bighest temperatures ; because, while in all the other experiments the quantity of hot water ranges from $9904.4 \mathrm{gr}$. to $10075.9 \mathrm{gr}$., in these it is, in all cases except one, more than 10100 gr. But according to Regnault's description of his second method, he uses less hot water in these experiments than in the others; hence we must admit that in copying the results of his second method into their appropriate places in the table of results of the first method, Regnault must have transferred a wrong series into the column headed "weight of hot water ;" probably he copied his values of $p-\pi$ instead of $\mathrm{P}-\mathrm{P}_{0}+p-\pi$, the true weight of hot water. At all events it will now be shown that he must have used the correct series of numbers in calculating the values of the specific heat.

For if we assume that in these thirteen experiments the level of the water in the calorimeter at $t$ always stood at the zero mark of the neck, we can estimate from Regnault's table the quantity of water $\mathrm{P}$ minus the small quantity contained in $n$ divisions of the neck. Subtracting the weight of cold water $\mathrm{P}_{0}-p+\pi$ given by Regnault, we get the weight of hot water added minus the small quantity contained in $n$ divisions of the neck. If we substitute this for $\mathrm{P}-\mathrm{P}_{0}+p-\pi$ in the above equation we shall get values of $x$ a little too large; if then the values for the specific heat given in these thirteen cases by Regnault are a little smaller than our calculated values, we can allow that he has calculated his values from the 
correct data, especially as they agree with his values in the twenty-seven other experiments.

I have applied this test to the thirteen experiments, and find that it is satisfied in all in the manner illustrated by the following six examples. The last column but one contains the values of $x$ as found approximately.

\begin{tabular}{|c|c|c|c|c|c|c|}
\hline \multirow{2}{*}{$\begin{array}{c}\text { No. of } \\
\text { experiment. }\end{array}$} & \multirow{2}{*}{ T. } & \multirow{2}{*}{$t_{0}$} & \multirow{2}{*}{$t$. } & \multicolumn{3}{|c|}{ Specific Heat. } \\
\hline & & & & Regnault. & Approximate. & Velten. \\
\hline \multirow{6}{*}{$\begin{array}{l}35 . \\
36 . \\
37 . \\
38 . \\
39 . \\
40 .\end{array}$} & \multirow{6}{*}{$\begin{array}{c}183 \\
\text { to } \\
190\end{array}$} & \multirow{6}{*}{$\begin{array}{c}13 \\
\text { to } \\
13 \cdot 6\end{array}$} & \multirow{6}{*}{$\begin{array}{l}28 \\
\text { to } \\
29\end{array}$} & $1 \cdot 01430$ & $1 \cdot 017$ & .9748 \\
\hline & & & & $1 \cdot 01499$ & $1 \cdot 019$ & .9749 \\
\hline & & & & $1 \cdot 01756$ & 1.019 & .9798 \\
\hline & & & & $1 \cdot 01487$ & $1 \cdot 019$ & .9804 \\
\hline & & & & $1 \cdot 01621$ & $1 \cdot 020$ & .9757 \\
\hline & & & & 1.01528 & $1 \cdot 020$ & $\cdot 9799$ \\
\hline
\end{tabular}

It is thus seen that Regnault's experiments are still reliable and remain the most valuable which we possess on the subject of the variation of the specific heat of water with temperature. Velten considers that his values calculated from Regnault's data confirm a formula which he has given for the specific heat of water deduced from experiments below $100^{\circ}$, and which makes the specific heat of water above $100^{\circ}$ less than unity; but we see from the above that his formula is quite out of harmony with Regnault's experiments.

Rankine ('Transactions of the Royal Society of Edinburgh,' xx.) has pointed out a correction which is required in Regnault's equation to allow for the kinetic energy of the hot water projected into the calorimeter by the highpressure steam ; but it is perhaps hardly necessary to apply it till greater precision is attained in the calorimetric measurements.

It would not have been worth while treating the matter at such length were it not for the large amount of experimental work that has already been spent on the subject and the importance of showing that the experiments of so skilled a physicist are not lost as they appeared to be, and of removing an unmerited reproach from so respected a name.

Melbourne,

May 25, 1888.

Phil. Mag. S. 5. Vol. 26. No. 160. Sept. 1888. X 